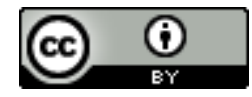

Esta obra está sob o direito de Licença Creative Commons Atribuição 4.0 Internacional.

\title{
QUALIDADE DA ÁGUA PARA O ABASTECIMENTO
}

\author{
Jesly Samara Rodrigues da Silva \\ Letícia Neves Rodrigues de Oliveira \\ Lucas dos Santos Rodrigues \\ Roseane de França Jesus \\ Thayná Brandão de Oliveira \\ Eduardo Cabral da Silva
}

\begin{abstract}
RESUMO
A qualidade no abastecimento vai além de um bom sistema de distribuição, envolve controle e qualidade desde a escolha dos mananciais, até o rigoroso comprimento das etapas de uma Estação de Tratamento de Água (ETA) que deve estar dentro dos padrões de portabilidade. No Brasil existe grandes índices de doenças causadas por veiculação hídrica e a falta dos serviços básicos como saneamento, atinge principalmente os mais pobres, gerando uma sobrecarga dos hospitais e gastos com prevenção e o tratamento da transmissão de doenças. Este presente artigo se propõe a avaliar por meio da revista sistemática integrativa o quanto a qualidade da água está relacionada com a saúde pública e qualidade de vida das pessoas. Analisando os artigos publicados na base de dados da plataforma Scielo entre os anos 2016 a 2021 sobre saúde pública, abastecimento de água, qualidade e saneamento básico, sendo adotado critério de inclusão e exclusão. A busca resultou em dez artigos com importantes conteúdos e informações com grande relevância para o contexto e a problemática proposta, sendo exploradas e discutidas. Portanto, é de extrema importância o investimento em saneamento básico assim como investimento para o controle de qualidade da água distribuída, o que acarretara em menos gastos e superlotações na saúde pública, além de diminuir a disseminação de doenças de veiculação hídrica.
\end{abstract}

Palavras-chave: Qualidade. Abastecimento. Saúde Pública. 


\section{INTRODUÇÃO}

A água é um bem natural que mais se relaciona com todos os aspectos da civilização humana, desde o cultivo de atividades agrícolas e industriais aos valores culturais e religiosos praticados em qualquer sociedade. Sendo um recurso natural indispensável, como componente bioquímico de seres vivos, fonte vital e como elemento de produção de bens de consumo (GOMES, 2011).

O uso irracional deste recurso vital vem ocasionando problemas de natureza qualitativa e quantitativa que compromete o futuro da civilização humana.

Em áreas urbanas esses problemas se relacionam com o rápido e desordenado crescimento da população em cidades com precária infraestrutura sanitária. Heller (2010), afirma que as necessidades de uso da água estão frequentemente diversificadas, existindo mais exigência por qualidade no abastecimento.

Para a boa qualidade no abastecimento de água se faz necessário o estabelecimento de novas tecnologias para tratamento e monitoramento constante da mesma. Dessa forma, já existem leis que regem tais procedimentos de controle e vigilância na qualidade da água para consumo humano e padrão potabilidade. A exemplo, cita-se a Portaria $\mathrm{n}^{\mathrm{o}}$ 2.912, publicada em 12 de dezembro de 2011, pelo ministério da saúde.

Da captação de água no manancial ao abastecimento doméstico, existes vários pontos e fatores críticos que podem facilitar contaminação do fluido - como o período chuvoso ou a má manutenção de reservatórios - podendo ser decisivos na saúde do consumidor, dessa forma, considerando os fatores de saúde pública, a qualidade no abastecimento de água se torna um fator imprescindível, seja na prevenção ou no agravo de doenças a população consumidora.

Assim, o presente artigo surgiu da inquietação na seguinte problemática: como a qualidade no abastecimento de água pode implicar na saúde do consumidor doméstico?

Para isto, partiu da consideração do recurso hídrico como um bem de direito comum, dando ênfase no abastecimento e distribuição do recurso como questões de saúde pública, considerando além disso, que a má qualidade no abastecimento do mesmo pode ser um veículo de doenças e agravo na saúde humana (Silva, et al., 2016, p. 1).

Além disso, objetiva uma revisão bibliográfica acerca do tema, onde será analisado e discutido, considerando as visões e considerações de outros autores, as questões de saúde humana e transmissão de doenças através do mal abastecimento de água e os procedimentos definidos por lei sobre tal qualidade no abastecimento e potabilidade do recurso para consumo humano.

\section{MÉTODOLOGIA}

O presente trabalho trata-se de uma revisão sistemática integrativa que se fundamentou em pesquisas analíticas baseadas em artigos científicos sobre a temática da qualidade da água para o abastecimento que pode implicar na saúde do consumidor doméstico. As informações foram colhidas na biblioteca virtual Scielo, utilizando os descritores abastecimento e distribuição combinados com o operador booleano And, conforme descrito no Quadro 1.

Os critérios de inclusão de artigos como referências bibliográficas foram a 
utilização de pelo menos $70 \%$ dos artigos publicados nos últimos cinco anos, que contemplassem a temática desse estudo e que concentrassem suas investigações no território nacional.
Os quadros a seguir detalham as etapas da pesquisa referente a essa revisão e os resultados obtidos.

\section{Quadro 1}

Detalhamento das etapas da Revisão Sistemática Integrativa.

\begin{tabular}{|c|c|c|c|}
\hline ETAPA & $\begin{array}{c}\text { TÓPICOS DE CADA } \\
\text { ETAPA }\end{array}$ & \multicolumn{2}{|c|}{ DETALHAMENTO DE CADA TÓPICO } \\
\hline \multirow[t]{14}{*}{$1^{\mathrm{a}}$} & Tema & \multicolumn{2}{|c|}{ Qualidade de água para o abastecimento } \\
\hline & Pergunta norteadora & \multicolumn{2}{|c|}{$\begin{array}{l}\text { Como a qualidade de água pode implicar na saúde do } \\
\text { consumidor doméstico? }\end{array}$} \\
\hline & Objetivo geral & \multicolumn{2}{|c|}{$\begin{array}{l}\text { Desenvolver uma revisão bibliográfica a cerca do tema } \\
\text { analisando e discutindo visões de diferentes, com foco } \\
\text { na saúde humana e transmissão de doenças provenientes } \\
\text { do mal abastecimento de agua. }\end{array}$} \\
\hline & Estratégias de busca & \multicolumn{2}{|c|}{$\begin{array}{c}\text { As informações foram colhidas na biblioteca virtual } \\
\text { SciELO, utilizando os descritores abastecimento e } \\
\text { distribuição, combinados com o operador booleano } \\
\text { And. }\end{array}$} \\
\hline & \multirow{3}{*}{$\begin{array}{l}\text { Bancos de } \\
\text { terminologias }\end{array}$} & Banco & Link \\
\hline & & DeSC & http://decs.bvs.br/ \\
\hline & & $\mathrm{MeSH}$ & https://www.ncbi.nlm.nih.gov/mesh \\
\hline & \multirow[t]{4}{*}{$\begin{array}{l}\text { Descritores livres e } \\
\text { estruturados }\end{array}$} & $\begin{array}{c}\text { Descrit } \\
\text { or }\end{array}$ & DeCS (Registro) \\
\hline & & $\begin{array}{l}\text { Abaste } \\
\text { ciment } \\
\text { o }\end{array}$ & 15285 \\
\hline & & $\begin{array}{l}\text { Saúde } \\
\text { pública }\end{array}$ & 36354 \\
\hline & & $\begin{array}{l}\text { Qualid } \\
\text { ade }\end{array}$ & 25106 \\
\hline & String de busca & \multicolumn{2}{|c|}{ Abastecimento And saúde pública } \\
\hline & \multirow[t]{2}{*}{ Bibliotecas Virtuais } & Bibliot & Link \\
\hline & & Scielo & $\begin{array}{c}\text { https://www.scielo.br/scielo.php?pid= } \\
\text { S1413- } \\
\text { 41522016000300615\&script=sci_artte } \\
\text { xthttps://www.scielosp.org/article/sde } \\
\text { b/2019.v43nspe3/8-19/ }\end{array}$ \\
\hline \multirow[t]{2}{*}{$2^{a}$} & $\begin{array}{l}\text { Período de coleta dos } \\
\text { dados }\end{array}$ & & \\
\hline & Critérios de inclusão & \multicolumn{2}{|c|}{$\begin{array}{l}\text { 8. Artigos (artigo científicos e free). } \\
\text { 9. Publicação (2016-2021). }\end{array}$} \\
\hline
\end{tabular}




\begin{tabular}{|c|c|c|}
\hline & Critérios de exclusão & 3. Artigos que não contemplam a temática \\
\hline $3^{\mathrm{a}}$ & $\begin{array}{l}\text { Número de trabalhos } \\
\text { selecionados para } \\
\text { revisão sistemática } \\
\text { integrativa a partir da } \\
\text { leitura dos agentes } \\
\text { indexadores das } \\
\text { publicações (tema, } \\
\text { descrição, ementa). }\end{array}$ & 10 \\
\hline $4^{\mathrm{a}}$ & $\begin{array}{c}\text { Categorias obtidas com } \\
\text { a análise dos } \\
\text { documentos } \\
\text { investigados online } \\
\text { gratuitos e de livre } \\
\text { acesso } \\
\end{array}$ & 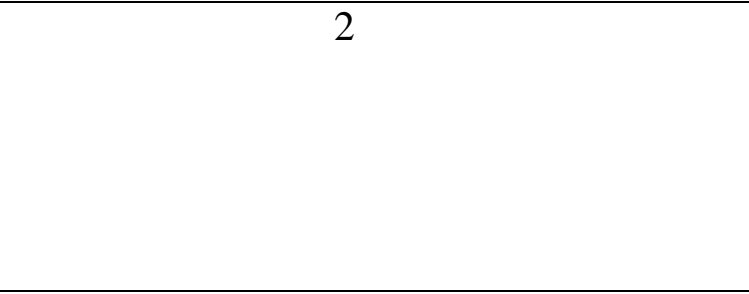 \\
\hline $5^{a}$ & $\begin{array}{l}\text { Análise, interpretação e } \\
\text { discussão dos resultados }\end{array}$ & Ver em "Resultados e Discussão" \\
\hline $6^{a}$ & $\begin{array}{l}\text { Apresentação da revisão } \\
\text { em formato de artigo, o } \\
\text { qual contemple } \\
\text { propostas para estudos } \\
\text { futuros }\end{array}$ & Este Artigo completo \\
\hline
\end{tabular}

Fonte: elaborada pelos autores.

\section{RESULTADOS}

O detalhamento sobre as strings de busca utilizadas na base de dados da Scielo, os respectivos dados quantitativos sobre os resultados dos artigos nas buscas estão dispostos no Quadro 2. Dentro dessa perspectiva, a string com maior quantidade de artigos encontrados dentro da temática foi "Saneamento básico And Saúde pública", com o total de 452 trabalhos, sendo que, desses, apenas 5 selecionados para compor os resultados e discussão.

\section{Quadro 2}

Corresponde ao total de documentos disponíveis nas plataformas consultadas e obtidos pelas strings de busca listadas no Quadro 1.

\begin{tabular}{|c|c|c|c|c|}
\hline String de busca & $\begin{array}{c}\text { Bases de } \\
\text { dados }\end{array}$ & $\begin{array}{c}\text { Total de } \\
\text { publicações } \\
\text { sem o filtro }\end{array}$ & $\begin{array}{c}\text { Publicações } \\
\text { disponíveis } \\
\text { após aplicar os } \\
\text { filtros }\end{array}$ & $\begin{array}{c}\text { Publicações } \\
\text { aproveitadas na } \\
\text { Revisão Sistemática } \\
\text { Integrativa }\end{array}$ \\
\hline $\begin{array}{c}\text { Abastecimento } \\
\text { And Saúde Pública }\end{array}$ & Scielo & 295 & 28 & 4 \\
\hline $\begin{array}{c}\text { Saneamento Básico } \\
\text { And Saúde pública }\end{array}$ & Scielo & 452 & 42 & 5 \\
\hline
\end{tabular}




\begin{tabular}{|l|c|c|c|c|}
\hline $\begin{array}{l}\text { Qualidade And } \\
\text { Abastecimento }\end{array}$ & Scielo & 353 & 26 & 1 \\
\hline
\end{tabular}

Fonte: elaborada pelos autores.

O Quadro 3 consiste no avaliação técnica dos artigos. O Quadro detalhamento dos 10 (dez) artigos mostra a autoria, o tema, o link e a data de selecionados após a aplicação dos critérios publicação e a conclusão dos artigos. de inclusão e exclusão, assim como, 


\section{QUADRO 3 DESCRIÇÃO DOS DOCUMENTOS (ARTIGOS) DE ACORDO COM OS CRITÉRIOS DE INCLUSÃO.}

\begin{tabular}{|c|c|c|c|c|c|}
\hline $\mathbf{N}^{\mathbf{0}}$ & Autor(a) & Tema & $\begin{array}{c}\text { Link da } \\
\text { publicação }\end{array}$ & $\begin{array}{c}\text { Data de } \\
\text { publicação }\end{array}$ & Conclusão \\
\hline 1 & $\begin{array}{c}\text { Suzana de Araújo } \\
\text { Silva; José } \\
\text { Aparecido da Silva } \\
\text { Gama; Nélia } \\
\text { Henriques Callado; } \\
\text { Vladimir Caramori } \\
\text { Borges de Souza. }\end{array}$ & $\begin{array}{c}\text { Saneamento básico } \\
\text { e saúde pública na } \\
\text { Bacia Hidrográfica } \\
\text { do Riacho } \\
\text { Reginaldo em } \\
\text { Maceió, Alagoas }\end{array}$ & $\begin{array}{c}\text { https://doi.org/ } \\
10.1590 / \text { s1413 }\end{array}$ & $\begin{array}{c}- \\
015220171469 \\
71\end{array}$ & $\begin{array}{c}\text { As bacias hidrográficas urbanas apresentam uma realidade muito } \\
\text { complexa no que se refere à qualidade das águas, geralmente afetadas } \\
\text { pela carência dos serviços de saneamento, com consequências diretas } \\
\text { sobre a saúde da população. Este trabalho buscou relacionar } \\
\text { ocorrência e incidência de doenças de veiculação hídrica com o } \\
\text { Índice de Salubridade Ambiental (ISA). O ISA utilizado baseia-se na } \\
\text { ocorrência, magnitude e abrangência de alagamentos e na qualidade e } \\
\text { abrangência da prestação dos serviços de abastecimento de água, } \\
\text { esgotamento sanitário e coleta de resíduos sólidos. Os resultados } \\
\text { indicam uma relação entre os indicadores que compóem o ISA e a } \\
\text { incidência de doenças específicas (relacionadas a determinado } \\
\text { componente do ISA), mas mostram também que a resolução espacial } \\
\text { e a forma de obtenção dos indicadores primários afetam } \\
\text { substancialmente os resultados[...] }\end{array}$ \\
\hline
\end{tabular}

Fonte: elaborada pelos autores. 


\begin{tabular}{|c|c|c|c|c|c|}
\hline 2 & $\begin{array}{c}\text { Nathalie Cruz; José } \\
\text { Carlos Mierzwa. }\end{array}$ & $\begin{array}{l}\text { Saúde pública e } \\
\text { inovações } \\
\text { tecnológicas para } \\
\text { abastecimento } \\
\text { público }\end{array}$ & $\begin{array}{c}\text { https://doi.org/ } \\
10.1590 / \mathrm{s} 0104 \\
- \\
129020201808 \\
24\end{array}$ & $03 / 02 / 2020$ & $\begin{array}{l}\text { A escassez de água em metrópoles brasileiras tem se agravado em } \\
\text { função das características de seu próprio desenvolvimento. A } \\
\text { expansão urbana desordenada e próxima a mananciais, junto com a } \\
\text { falta de infraestrutura para estes novos núcleos habitacionais, tem } \\
\text { favorecido a degradação dos mananciais utilizados para } \\
\text { abastecimento público. Em razão disto, a população fica mais } \\
\text { suscetível às doenças de veiculação hídrica. Independentemente dos } \\
\text { tipos de contaminantes presentes na água, busca-se aprimorar as } \\
\text { tecnologias tradicionalmente empregadas nos processos de } \\
\text { tratamento hídrico a fim de garantir uma água segura para o } \\
\text { abastecimento da população, sem considerar as inovações } \\
\text { tecnológicas neste setor. Assim, o presente estudo busca evidenciar a } \\
\text { necessidade de melhorar as ações de tratamento de água e esgotos } \\
\text { realizadas atualmente no país, em função dos riscos associados à } \\
\text { saúde pública. Busca-se também analisar o reúso potável direto e } \\
\text { como esta prática pode ser uma solução para promover uma água de } \\
\text { qualidade e suprir a demanda de grandes centros urbanos em situação } \\
\text { de escassez hídrica. [...] }\end{array}$ \\
\hline 3 & $\begin{array}{l}\text { Maria Helena } \\
\text { Martins Mendonça } \\
\text { Sthefany Angely } \\
\text { Moraes Roseno; } \\
\text { Thayany Ruanny } \\
\text { Leite Cachoeira; } \\
\text { Ákylla Fernanda } \\
\text { Souza Silva; Paula } \\
\text { Regina Luna de } \\
\text { Araújo Jácome; }\end{array}$ & $\begin{array}{c}\text { Análise } \\
\text { bacteriológica da } \\
\text { água de consumo } \\
\text { comercializada por } \\
\text { caminhões-pipa }\end{array}$ & $\begin{array}{l}\text { https://doi.org/ } \\
\text { 10.4136/ambi- } \\
\text { agua.1934 }\end{array}$ & $18 / 02 / 2017$ & $\begin{array}{l}\text { Assim, o presente estudo teve como objetivo avaliar a qualidade } \\
\text { bacteriológica da água para consumo direto (ingestão) comercializada } \\
\text { por caminhões-pipa, destinada ao abastecimento da cidade de } \\
\text { Caruaru-PE. Foram analisadas } 10 \text { amostras, obtidas de cinco } \\
\text { caminhões-pipa, por meio da Técnica dos Tubos Múltiplos, para a } \\
\text { identificação de Pseudomonas aeruginosa e do grupo coliforme e, da } \\
\text { técnica pour plate, para a contagem de bactérias heterotróficas. Os } \\
\text { resultados revelaram a presença dos grupos bacterianos testados na } \\
\text { maioria das amostras analisadas. Foi verificado que o tempo era um } \\
\text { fator que contribuía para o aumento do índice de contaminação. }\end{array}$ \\
\hline
\end{tabular}




\begin{tabular}{|c|c|c|c|c|c|}
\hline & $\begin{array}{l}\text { Agenor Tavares } \\
\text { Jácome Júnior. }\end{array}$ & & & & $\begin{array}{l}\text { Conclui-se que esse tipo de comércio acaba fornecendo uma água que } \\
\text { não atende aos requisitos de potabilidade e com um alto risco de } \\
\text { contaminação, sendo imprópria para o consumo humano. [...] }\end{array}$ \\
\hline 4 & $\begin{array}{l}\text { Lorrayne Belotti; } \\
\text { Soraya da Rocha } \\
\text { Brandão; Karina } \\
\text { Tonini dos Santos } \\
\text { Pacheco; Paulo } \\
\text { Frazão; Carolina } \\
\text { Dutra Degli } \\
\text { Esposti. }\end{array}$ & $\begin{array}{l}\text { Vigilância da } \\
\text { qualidade da água } \\
\text { para consumo } \\
\text { humano: } \\
\text { potencialidades e } \\
\text { limitações com } \\
\text { relação à } \\
\text { fluoretação } \\
\text { segundo os } \\
\text { trabalhadores }\end{array}$ & $\begin{array}{l}\text { https://doi.org/ } \\
10.1590 / 0103- \\
11042019 \text { s304 }\end{array}$ & $13 / 01 / 2020$ & $\begin{array}{l}\text { Os trabalhadores da vigilância da água exercem importante papel na } \\
\text { implementação do Programa Nacional de Vigilância da Qualidade da } \\
\text { Água para Consumo Humano e detêm informações sugestivas do } \\
\text { grau de estruturação e da institucionalidade das práticas no âmbito } \\
\text { local das organizações sanitárias. O estudo objetivou descrever as } \\
\text { potencialidades e as limitações relativas à vigilância da fluoretação da } \\
\text { água em uma região metropolitana brasileira segundo a visão dos } \\
\text { trabalhadores. Realizaram-se entrevistas semiestruturadas com } \\
\text { profissionais de sete municípios da região metropolitana do estado do } \\
\text { Espírito Santo, Brasil, que foram gravadas, transcritas na íntegra e } \\
\text { interpretadas segundo a Análise de Conteúdo Temática. Os resultados } \\
\text { permitiram a elaboração das categorias: recomendações da legislação } \\
\text { e a prática do heterocontrole da concentração do fluoreto; } \\
\text { dificuldades e potencialidades do processo de trabalho; disseminação } \\
\text { das informações para a sociedade. A maioria dos trabalhadores seguia } \\
\text { as recomendações da legislação vigente no período das entrevistas } \\
\text { (Portaria MS no 2.914/2011), porém, notou-se a necessidade de } \\
\text { adequações estruturais e organizacionais. O processo de vigilância do } \\
\text { fluoreto enfrenta problemas que envolvem a coleta da amostra, as } \\
\text { análises e a divulgação dos resultados. É nítida a necessidade de } \\
\text { maior priorização e alocação de recursos para ampliação e } \\
\text { qualificação da vigilância dessa medida de saúde pública. [...] }\end{array}$ \\
\hline 5 & $\begin{array}{l}\text { Josiane Teresinha } \\
\text { Matos de Queiroz; }\end{array}$ & $\begin{array}{l}\text { Novos } \\
\text { pressupostos para o } \\
\text { saneamento no }\end{array}$ & $\begin{array}{l}\text { https://doi.org/ } \\
\text { 10.1590/0102- } \\
\text { 311x00223719 }\end{array}$ & $08 / 05 / 2020$ & $\begin{array}{l}\text { Nesse contexto, serviços de saneamento podem ser determinantes } \\
\text { importantes para a incidência e prevalência de arboviroses e estes têm } \\
\text { sido negligenciados nas estratégias de controle das doenças. Ressalta- }\end{array}$ \\
\hline
\end{tabular}




\begin{tabular}{|c|c|c|c|c|c|}
\hline & $\begin{array}{c}\text { Priscila Neves } \\
\text { Silva; Léo Heller. }\end{array}$ & $\begin{array}{c}\text { controle de } \\
\text { arboviroses no } \\
\text { Brasil }\end{array}$ & & & $\begin{array}{l}\text { se que a implementação dos serviços não tem sido orientada pela } \\
\text { ótica dos DHAES, que prevê importantes instrumentos analíticos da } \\
\text { real situação do território, apontando diretrizes para o planejamento. } \\
\text { Portanto, apresentam-se três premissas para a discussão sobre a } \\
\text { relação entre a ocorrência de arboviroses e a oferta de serviços de } \\
\text { saneamento, considerando a inclusão dos pressupostos dos DHAES } \\
\text { como elemento importante para o controle dessas doenças. [...] }\end{array}$ \\
\hline 6 & $\begin{array}{c}\text { Antonio Carlos de } \\
\text { Souza Neto; Paulo } \\
\text { Frazão; }\end{array}$ & $\begin{array}{c}\text { Princípios } \\
\text { invocados numa } \\
\text { política } \\
\text { intersetorial de } \\
\text { saúde: o caso da } \\
\text { fluoretação da } \\
\text { água no Brasil }\end{array}$ & $\begin{array}{c}\text { https://doi.org/ } \\
10.1590 / \mathrm{s} 0104 \\
- \\
129020201900 \\
48\end{array}$ & $20 / 03 / 2020$ & $\begin{array}{l}\text { O objetivo foi identificar princípios invocados numa política } \\
\text { intersetorial de saúde, tomando como caso uma proposta legislativa } \\
\text { de revogação da fluoretação da água no Brasil apresentada em } 2003 \text {. } \\
\text { Realizou-se estudo descritivo por meio de pesquisa documental, na } \\
\text { qual foram selecionados registros gerados na tramitação do Projeto de } \\
\text { Lei no 510/2003 na Câmara dos Deputados. Buscou-se destacar } \\
\text { estratégias discursivas utilizadas pelos atores conforme o jogo de } \\
\text { interesses e o contexto conflitivo, utilizando-se o institucionalismo } \\
\text { histórico como referencial teórico. O Projeto de Lei tramitou } 13 \\
\text { meses, passando pelo Plenário, por três comissões, e sendo } \\
\text { arquivado. Três deputados de partidos distintos, órgãos do Poder } \\
\text { Executivo federal, agências reguladoras e entidades representativas } \\
\text { da categoria odontológica, da saúde pública/coletiva, da engenharia } \\
\text { sanitária e das empresas de saneamento participaram diretamente do } \\
\text { debate em que emergiram os princípios da segurança da intervenção, } \\
\text { dos custos econômicos e do direito à saúde. Em relação às estratégias } \\
\text { discursivas utilizadas, os principais elementos invocados no debate da } \\
\text { política intersetorial de saúde foram o princípio da incerteza, criando- } \\
\text { se falsas categorias científicas a fim de sobrevalorizar os efeitos } \\
\text { desfavoráveis e sustentar a implementação de medidas } \\
\text { individualizantes; e os princípios morais que definem diferentes tipos }\end{array}$ \\
\hline
\end{tabular}




\begin{tabular}{|c|c|c|c|c|c|}
\hline & & & & & $\begin{array}{l}\text { de bens econômicos e dimensões de liberdade associadas ao exercício } \\
\text { de direitos. [...] }\end{array}$ \\
\hline 7 & $\begin{array}{c}\text { Marcio Ricardo } \\
\text { Salla, Elias Sá; } \\
\text { Pedro Augusto } \\
\text { Silva Costa } \\
\text { Ferreira; Nágela } \\
\text { Aparecida de Melo. }\end{array}$ & $\begin{array}{l}\text { Relação entre } \\
\text { saneamento } \\
\text { básico e saúde } \\
\text { pública em } \\
\text { Bissau, Guiné - } \\
\text { Bissau }\end{array}$ & $\begin{array}{c}\text { https://doi.org/ } \\
10.1590 / \mathrm{S} 0104 \\
- \\
129020191807 \\
05\end{array}$ & $09 / 12 / 2019$ & $\begin{array}{l}\text { Este artigo avalia a relação de custos entre a saúde pública e a } \\
\text { implementação do saneamento básico na capital da Guiné-Bissau. } \\
\text { Analisaram-se seis cenários, incluindo três opções para o sistema de } \\
\text { esgotamento sanitário (sistema coletivo com rede coletora e estação } \\
\text { elevatória de esgoto, sistema simplificado individual por latrina e } \\
\text { sistema coletivo completo com rede coletora, estação elevatória e } \\
\text { estação de tratamento de esgoto) e duas para o sistema de } \\
\text { abastecimento de água (captação direta e sistema completo com } \\
\text { captação, reservação e distribuição). Quanto à saúde pública, } \\
\text { consideraram-se os custos com recursos humanos e programas de } \\
\text { assistência social, medicamentos, vacinas e internações relacionados } \\
\text { às doenças de veiculação hídrica, malária e cólera. A relação de } \\
\text { custos de } 4,29 \text { no cenário mais eficiente de saneamento básico foi } \\
\text { similar ao valor encontrado na literatura da área. Em outras palavras, } \\
\text { para cada dólar investido no saneamento básico existe uma economia } \\
\text { aproximada de } 4,3 \text { dólares com a saúde. Além disso, as curvas } \\
\text { potenciais da relação de custos, em razão do cenário, são muito úteis } \\
\text { em países pobres da África, Ásia e América Latina, regiões que } \\
\text { carecem de dados relacionados aos gastos com saúde pública e } \\
\text { saneamento básico. [...] }\end{array}$ \\
\hline
\end{tabular}




\begin{tabular}{|c|c|c|c|c|c|}
\hline 8 & $\begin{array}{c}\text { Cezarina Maria } \\
\text { Nobre Souza; Léo } \\
\text { Heller. }\end{array}$ & $\begin{array}{l}\text { O controle social } \\
\text { em saneamento e } \\
\text { em saúde: análise } \\
\text { comparativa com } \\
\text { base nos marcos } \\
\text { legais federais } \\
\text { brasileiros }\end{array}$ & $\begin{array}{l}\text { https://doi.org/ } \\
\text { 10.1590/1413- } \\
81232018241 . \\
35012016\end{array}$ & $01 / 2019$ & $\begin{array}{l}\text { A comparação entre os marcos legais federais brasileiros das áreas de } \\
\text { saúde e de saneamento, sob a perspectiva do controle social, é o fio } \\
\text { condutor deste trabalho, tendo em vista o pioneirismo da primeira e } \\
\text { sua possível influência sobre a segunda. O esforço comparativo foi } \\
\text { realizado a partir de seis critérios analíticos: mecanismos de controle } \\
\text { social definidos; caráter conferido ao controle social; } \\
\text { responsabilidade, recomendações e apoio para viabilizar o controle } \\
\text { social; acesso à informação; controle sobre o uso dos recursos; } \\
\text { controle da implementação das deliberações. Avaliaram-se } \\
\text { possibilidades de o marco do saneamento se beneficiar das } \\
\text { formulações no campo da saúde e lograr produzir práticas mais } \\
\text { efetivas de controle social na condução dessa política pública. Os } \\
\text { resultados revelam que, mesmo tendo recebido alguma influência da } \\
\text { área de saúde, o marco do saneamento é mais restrito e tem menor } \\
\text { potencialidade de produzir práticas mais efetivas, uma vez que } \\
\text { apresenta: 1) mecanismos mais restritivos por não serem } \\
\text { necessariamente deliberativos; 2) ausência de uma política de } \\
\text { formação de conselheiros e de educação popular como incentivo e } \\
\text { fortalecimento ao controle social; 3) ausência de mecanismos efetivos } \\
\text { voltados para a fiscalização do uso dos recursos.[...] }\end{array}$ \\
\hline
\end{tabular}




\begin{tabular}{|c|c|c|c|c|c|}
\hline 9 & $\begin{array}{c}\text { Julimara de Souza } \\
\text { Costa } \\
\text { Oliveira;CAmanda } \\
\text { de Mattos } \\
\text { MedeirosCLarissa } \\
\text { Gonçalves Castor; } \\
\text { Rose Ferraz Carmo; } \\
\text { Paula Dias } \\
\text { Bevilacqua. }\end{array}$ & $\begin{array}{l}\text { Soluções } \\
\text { individuais de } \\
\text { abastecimento de } \\
\text { água para } \\
\text { consumo humano: } \\
\text { questões para a } \\
\text { vigilância em } \\
\text { saúde ambiental }\end{array}$ & $\begin{array}{c}\text { https://doi.org/ } \\
\text { 10.1590/1414- } \\
462 \text { X2017000 } \\
20371\end{array}$ & $06 / 2017$ & $\begin{array}{l}\text { Ainda são vários os desafios da Vigilância da Qualidade da Água } \\
\text { para Consumo Humano (VQACH) nos municípios, principalmente } \\
\text { em relação às soluções alternativas individuais de abastecimento } \\
\text { (SAIs), as quais podem apresentar ágeis mudanças, especialmente, } \\
\text { em cenários de restrição hídrica. Analisaram-se os perigos } \\
\text { relacionados às SAIs cadastradas em município de pequeno porte da } \\
\text { Zona da Mata de Minas Gerais, integrando dados relativos à } \\
\text { notificação de casos de doença diarreica aguda (DDA). Entre } \\
\text { setembro de } 2013 \text { e janeiro de } 2015 \text {, foram cadastradas/inspecionadas } \\
584 \text { SAIs, das quais } 19,7 \% \text { localizadas na área urbana e } 80,3 \% \text { na } \\
\text { área rural. Além disso, } 92,6 \% \text { eram utilizadas para fornecimento de } \\
\text { água para consumo humano, atendendo a } 2.323 \text { pessoas. Maior } \\
\text { proteção e/ou cuidado foram observados na área urbana, assim como } \\
\text { maior ocorrência de focos de contaminação (o mais frequente foi o } \\
\text { esgoto sanitário). Apenas para área urbana foi identificada correlação } \\
\text { estatisticamente significante entre número de SAIs e casos } \\
\text { notificados de DDA (p=0,002). Reforça-se a necessidade de } \\
\text { investimentos e a priorização de ações da VQACH direcionadas às } \\
\text { SAIs, já que não são alvos de ações de controle da qualidade da água, } \\
\text { bem como o aumento da cobertura da população por serviços de } \\
\text { saneamento. [...] }\end{array}$ \\
\hline 10 & $\begin{array}{c}\text { Paulo Rubens } \\
\text { Guimarães } \\
\text { Barrocas Flavia } \\
\text { Franchini de Mattos } \\
\text { Moraes Ana } \\
\text { Cristina Augusto } \\
\text { Sousa }\end{array}$ & $\begin{array}{l}\text { Saneamento é } \\
\text { saúde? O } \\
\text { saneamento no } \\
\text { campo da saúde } \\
\text { coletiva }\end{array}$ & $\begin{array}{c}\text { https://doi.org/ } \\
10.1590 / \text { S0104 } \\
- \\
597020190001 \\
00003\end{array}$ & $01 / 2019$ & $\begin{array}{l}\text { Milhares de crianças no mundo ainda morrem por doenças causadas } \\
\text { pela falta de saneamento. Entretanto, o saneamento segue quase } \\
\text { invisível na agenda da saúde brasileira. O objetivo deste estudo é } \\
\text { investigar a relevância dada ao tema pelos pesquisadores do campo } \\
\text { da saúde coletiva. Para isso mapeou-se a presença do tema nos } \\
\text { grupos de pesquisa do CNPq, nos periódicos científicos nacionais e } \\
\text { nos programas de pós-graduação em saúde coletiva. Os resultados }\end{array}$ \\
\hline
\end{tabular}




\begin{tabular}{|l|l|l|l|}
\hline & & & $\begin{array}{c}\text { mostraram que poucos desses programas abordam o tema. Assim, } \\
\text { poucos grupos de pesquisa em saúde coletiva estudam e publicam } \\
\text { sobre saneamento nos periódicos avaliados. Fatores que poderiam } \\
\text { estar associados à aparente baixa relevância dada ao tema pela } \\
\text { comunidade acadêmica da saúde coletiva são discutidos. [...] }\end{array}$ \\
\hline
\end{tabular}


O corpo textual foi analisado por meio da frequência de palavras, que originou a nuvem de palavras (Figura 1) criada na Plataforma online WordArt. Esta ferramenta agrupa e organiza graficamente as palavras-chave evidenciando-as as mais frequentes.

Figura 1 - Nuvem de palavras

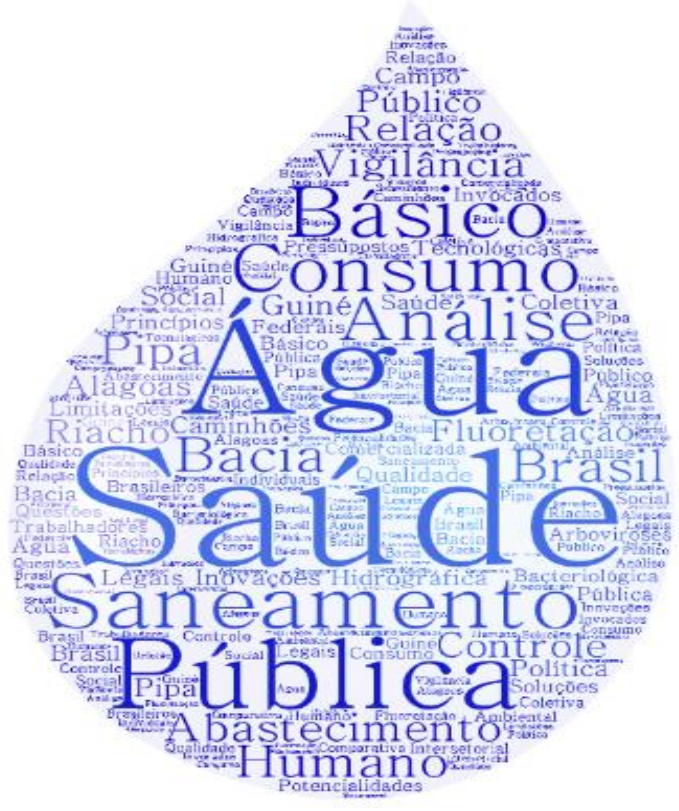

Fonte: elaborada pelos autores.

Por meio da Figura 1, foi possível observar que as palavras em evidência na nuvem pertencem as categorias desenvolvidas a partir da análise de conteúdo de Bardin. Todas as categorias derivam da sua frequência (Tabela 1), que diz respeito ao seu quadro referencial. Em consonância ao objetivo deste trabalho, optou-se por descrever as palavras que apresentaram frequência total no texto e, a partir de seus sentidos nos campos textuais, tinham maior relevância para as representações sociais sobre as relações entre saúde pública e saneamento básico, consumo e qualidade da água, como apresentado na Figura1.

TABELA 1.

FREQUENCIA DAS PALAVRAS PRESENTES NOS TEXTOS PUBLICADOS NAS PLATAFORMAS DA SCIELO.

\begin{tabular}{c|c}
\hline PALAVRAS & FREQUÊNCIA \\
\hline Saneamento & 6 \\
\hline Água & 4 \\
\hline Pública & 3 \\
\hline Consumo & 3 \\
\hline Básico & 2 \\
\hline Abastecimento & 2 \\
\hline
\end{tabular}




\begin{tabular}{|c|c|}
\hline Análise & 2 \\
\hline Vigilância & 2 \\
\hline Humano & 2 \\
\hline Relação & 2 \\
\hline Fluoretação & 2 \\
\hline Controle & 2 \\
\hline Brasil & 2 \\
\hline Bacia & 1 \\
\hline Hidrográfica & 1 \\
\hline Riacho & 1 \\
\hline Alagoas & 1 \\
\hline Inovações & 1 \\
\hline Tecnológicas & 1 \\
\hline Público & 1 \\
\hline Bacteriológica & 1 \\
\hline Comercializada & 1 \\
\hline Caminhões & 1 \\
\hline Pipa & 1 \\
\hline Qualidade & 1 \\
\hline Potencialidades & 1 \\
\hline Limitações & 1 \\
\hline Trabalhadores & 1 \\
\hline Pressupostos & 1 \\
\hline Arboviroses & 1 \\
\hline Princípios & 1 \\
\hline Invocados & 1 \\
\hline Política & 1 \\
\hline Intersetorial & 1 \\
\hline Guiné & 1 \\
\hline Campo & 1 \\
\hline Coletiva & 1 \\
\hline Social & 1 \\
\hline Comparativa & 1 \\
\hline Legais & 1 \\
\hline Federais & 1 \\
\hline Brasileiros & 1 \\
\hline Soluções & 1 \\
\hline Individuais & 1 \\
\hline Questões & 1 \\
\hline Ambiental & 1 \\
\hline
\end{tabular}

Fonte: elaborada pelos autores. 


\section{DISCUSSÕES}

As categorias de discussão abaixo, oriundas da análise das frequências das palavras (Tabela 1) e da evidência dessas diante da nuvem (Figura 1), assim como, da análise técnica das temáticas abordadas nos artigos selecionados e dispostos no Quadro 3, deram subsídio para discussões pertinentes a temática central do artigo. Abaixo seguem os 2 (dois) categorias elaboradas.

\section{O CONSUMO E A QUALIDADE DA ÁGUA}

No Brasil, o direito de alcance à água em qualidade e quantidade compatível com o padrão de potabilidade regido pela legislação válida é uma importante concessão do Sistema Único de Saúde (SUS), instrumentalizada pela Vigilância da Qualidade da Água para Consumo Humano (VQACH). A atuação desse sistema concebe as formas de abastecimento da água para o consumo humano, de modo individual ou coletivo, nas diversas áreas (OLIVEIRA, 2017).

A vigilância da qualidade da água engloba atividades de monitoramento $\mathrm{e}$ inspeção, que precisam de indicadores físico-químicos, operacionais e microbiológicos da água, assim como indicadores ambientais, sanitários e epidemiológicos. Uma das dificuldades é a garantia de uma avaliação integrada, na qual é compreendida como interpretação coletiva de dados sobre a qualidade da água para consumo humano no decorrer do abastecimento e consumo (FORTES; BARROCAS; KLIGERMAN, 2019).

No Brasil, também possui um sistema com a finalidade de auxiliar no gerenciamento de riscos à saúde associado ao abastecimento de água para consumo humano, que é o Sisagua (Sistema de
Informação de Vigilância da Qualidade da Água para Consumo Humano). As informações formadas pelo Sisagua são empregues na análise de situação de saúde relacionada ao abastecimento de água para o consumo humano, com intuito de diminuir os riscos relacionados ao consumo de água que estão fora do padrão de potabilidade (OLIVEIRA JUNIOR, 2019).

A disponibilidade a água potável, é de fato um direito da pessoa humana, este direito deve ser garantido sob qualquer perspectiva de disponibilidade quantitativa e qualitativa. Porém no que diz respeito a qualidade, o tratamento não é o único modo de assegurar o acesso. Artifícios como o da vigilância, direcionadas aos padrões normativos de potabilidade, tornam-se fundamentais com relação ao atendimento desde componente. (FORTES; BARROCAS; KLIGERMAN, 2019).

Normativamente, o método de vigilância já está estabelecido no contexto brasileiro, no entanto, no campo prático, os desafios são diversos. Dentro de distintas ações essenciais ao objetivo da vigilância em qualidade de água, as de informação diversas vezes são delegadas a um segundo plano. (FORTES; BARROCAS; KLIGERMAN, 2019).

\section{AS RELAÇÕES ENTRE SAÚDE PÚBLICA E SANEAMENTO BÁSICO}

A Lei 11.445 estabelece diretrizes nacionais para instalações de saneamento básico, que hoje é considerado um conjunto de ações de abastecimento de água, esgotamento sanitário, manejo de resíduos sólidos e manejo das águas pluviais, assim como a definição de outros conteúdos importantes (MENEZES, 2014)

Segundo Silva (2018) em 2020, o Comitê das Nações Unidas sobre os Direitos Econômicos, Sociais e Culturais 
elaborou o Comentário Geral $\mathrm{n}^{\mathrm{o}} 15$ sobre o direito humano à água. Segundo este comentário o direito à água se enquadra no direito a uma vida com qualidade e está intimamente relacionado com o direito à saúde, alimentação e moradia digna, previstos no Tratado Internacional sobre Direitos Econômicos, Sociais e Culturais.

Silva (2018) também estabelece que o acesso ao esgotamento sanitário é essencial para que o direito à água seja atingido.

O saneamento básico é compreendido como um conjunto de ações para promover e garantir o bem-estar e a segurança da população e a geração de ruído por meio de rede de tratamento de esgoto, abastecimento de água, coleta e disposição final de resíduos e drenagem. Além de consubstanciar melhorias na saúde da população no quadro sanitário condições adequadas de saneamento e qualidade de vida, contribuindo na redução de recursos econômicos nos cofres públicos, já que as doenças por via hídricas sobrecarregam o sistema de saúde. (SANTOS, 2018).

A saúde está estreitamente ligada ao saneamento básico, o aumento das doenças infecciosas é diretamente ligado a qualidade da água e proporcional a falta de instalações sanitária. A ocorrência desta levam a redução da produtividade, aumento dos custos e das despesas médicas (FARIAS, 2020).

No Brasil, em 2017, as internações hospitalares de pacientes no Sistema Único de Saúde (SUS) por doenças causadas pela escassez de saneamento básico e acesso à água de qualidade produziram um custo de R\$ 100 milhões. Segundo dados do Ministério da Saúde, foram um total de 263,4 mil internações. No mundo, mais de 1,5 milhão de crianças vieram a óbito graças ao fornecimento inapropriado de água. A dengue, Zika e Chikungunya são exemplos pertinentes de doenças ligadas a essa escassez, sendo responsáveis respectivamente por 1.544.987, 10.768 e 132.205 em números de casos. Quanto aos falecimentos, confirmaram-se 782 por dengue, 3 por Zika e 92 por Chikungunya, ainda no mesmo ano. (QUEIROZ, SILVA, HELLER, 2020).

Amplificar o atendimento a serviços de água e saneamento traduz ganhos claros em termos de saúde, já que doenças relacionadas com o contato direto a fezes humanas ou esgoto a céu aberto provocam cerca de um milhão de mortes por ano no mundo. "No caso da saúde pública, essa relação existe porque a falta de infraestrutura sanitária aumenta a proliferação de pragas e micro-organismos que manifestam doenças como as verminoses e também o contato da população com esses ambientes insalubres (BRK AMBIENTAL, 2021). Dessa maneira, fica explícito que o saneamento tem um impacto direto com a saúde coletiva. Quanto menor forem as ocorrências das doenças, menor será o índice de internações e por consequência, menores custos para os cofres públicos serão exigidos.

\section{CONCLUSÃO}

A falta de saneamento básico nas regiões menos favorecidas, assim como a escassez no controle da qualidade da água para o consumo humano, ainda são problemas bastante corriqueiros nas periferias brasileira e Zona Rurais.

No contexto desse artigo foi demostrado a ligação entre saúde pública e qualidade da água para abastecimento, o quanto é importante a relação entre essas duas temáticas. Tendo em vista o índice de 
pessoas doente com doenças transmitidas por veiculação hídrica, que sobrecarregam os hospitais.

O problema se agrava quando o serviço de abastecimento é interrompido por irregularidade de precipitação, para a recarrega dos mananciais ou por obstrução das tubulações. A população procura outras fontes de abastecimento como carros-pipas,

\section{REFERÊNCIAS}

GOMES, M.A.F. Água: sem ela seremos o planeta Marte de amanhã. Disponível em http://webmail.cnpma.embrapa.br/down_hp 1464.pdf (on line). 2011. Acesso em 13 mai. 2021.

HELLER, L. Abastecimento de água para consumo humano. Léo Heller, Valter Lúcio de Pádua (organizadores). - Belo Horizonte: Editora UFMG. 2010.

SILVA, Leandro; LOPES, Laudicéia. AMARAL, Luiz. Qualidade da água de abastecimento público do município de Jaboticabal, SP. Eng Sanit Ambient, v. 21, n.3, set. 2016. Disponível em: https://www.scielo.br/pdf/esa/v21n3/18094457-esa-21-03-00615.pdf. Acesso em:14 mai. 2021.

MENEZES, Paulo Renato. A Lei 11.445: o novo marco regulatório do saneamento no Brasil e seu impacto nas empresas públicas de água e esgoto: um estudo de caso. 2014. SANTOS, Fernanda Flores Silva dos; FILHO, José Daltro; et.al. O desenvolvimento do saneamento básico no Brasil e as consequências para a saúde pública. Disponível em:. Acesso em: $11 / 06 / 2021$ que nem sempre são abastecidos por fontes com portabilidade para o consumo humano.

Portanto faz necessário a atuação de políticas públicas que buscam expandir os serviços de abastecimento e saneamento, para localidades com situações mais precárias, com o intuito de diminuir os índices de doenças por veiculação hídrica e melhorar a qualidade de vida das pessoas FARIAS, Luis Arthur Brasil Gadelha; COLARES, Matheus Pessoa; et.al. O papel da atenção primária no combate ao Covid19: impacto na saúde pública e perspectivas futuras. Disponível em: < https://bityli.com/tIw3G>. Acesso em: 11/06/2021.

QUEIROZ, Josiane Teresinha Matos de; SILVA, Priscila Neves; HELLER, Léo. Novos pressupostos para o saneamento no controle de arboviroses no Brasil.

FORTES, Ana Carolina Chaves, BARROCAS, Paulo Rubens Guimarães e KLIGERMAN, Débora Cynamon A vigilância da qualidade da água e o papel da informação na garantia do acesso. Saúde em Debate [online]. 2019, v. 43, n. spe3 [Acessado 12 Junho 2021] , pp. 20-34. Disponível em: <https://doi.org/10.1590/010311042019S302>.

OLIVEIRA, Julimara de Souza Costa et al. Soluções individuais de abastecimento de água para consumo humano: questões para a vigilância em saúde ambiental. Cadernos Saúde Coletiva (online). 2017, v. 25, n. 2 (Acessado 12 Junho 2021), pp. 217-224. Disponível em: $<$ https://doi.org/10.1590/1414462X201700020371>. 
OLIVEIRA JUNIOR, Aristeu de et al.

Sistema de Informação de Vigilância da

Qualidade da Água para Consumo Humano

(Sisagua): características, evolução e

aplicabilidade. Epidemiol. Serv. Saúde,

Brasília, v. 28, n. 1, e2018117, mar. 2019.

Disponível em

<http://scielo.iec.gov.br/scielo.php?script=s

ci_arttext\&pid=S1679-

$49742019000100028 \& \operatorname{lng}=$ pt\&nrm=iso $>$. acessos em 12 jun. 2021.

QUEIROZ, Josiane Teresinha Matos de;

SILVA, Priscila Neves; HELLER, Léo.

Novos pressupostos para o saneamento no

controle de arboviroses no Brasil. Cad.

Saúde Pública 2020; 36(4):e00233719.

Disponível em

<https://doi.org/10.1590/0102-

311X00223719>. Acesso em: 14 jun. 2021.

AMBIENTAL, bkr. Os impactos da relação

entre saneamento básico e saúde pública.

Disponível em: <

https://blog.brkambiental.com.br/saneamen

to-basico-e-saude-publica/> . Acesso em:

14 jun. 2021. 